\title{
Regionalismo à mesa: uma análise das práticas de consumo de alimentos das donas de casa de Santa Maria (RS)
}

\author{
Regionalism at the table: an analysis of food consumption \\ practices of housewives in Santa Maria (RS)
}

Tayne Alcântara Araújo ${ }^{[a]}$, Milena Carvalho Bezerra Freire de Oliveira-Cruz ${ }^{[b]}$, Laura Hastenpflug Wottrich ${ }^{[c]}$

\footnotetext{
[a] Graduada em Comunicação Social - Publicidade e Propaganda pela Universidade Federal de Santa Maria (UFSM), Santa Maria, RS Brasil, email: taynealcantara@yahoo.com.br

[b] Professora do Departamento de Ciências da Comunicação da Universidade Federal de Santa Maria (UFSM); Doutoranda do Programa de Pós-Graduação em Comunicação da Universidade Federal de Santa Maria (UFSM), Santa Maria, RS - Brasil, email: milena.freire@ terra.com.br

${ }^{[c]}$ Mestre em Comunicação Midiática pela Universidade Federal de Santa Maria (UFSM), Santa Maria, RS - Brasil, email:lwottrich@gmail.com
}

\section{Resumo}

Considerando a relação entre comunicação e consumo como palco para observar a cultura contemporânea, o artigo objetiva refletir como o regionalismo influencia o consumo de alimentos entre donas de casa residentes em Santa Maria/RS. O trabalho se focou no acompanhamento da rotina de seis donas de casa, pertencentes às classes dominante, média e popular, observando o consumo de alimentos nos supermercados, as suas residências e as práticas diárias de alimentação. Os métodos aplicados para a pesquisa incluem a etnografia, observação participante e a entrevista em profundidade. Como resultados, percebemos que o regional está presente no consumo de alimentos de forma mais direta nas referências culturais, escolhas de ingredientes rituais e do que efetivamente na escolha das marcas.

Palavras-chave: Consumo de alimentos, Regionalismo, Gaúcho, Antropologia do consumo. 


\begin{abstract}
Considering the relationship between communication and consumption as a stage to observe the contemporary culture, this article reflects how regionalism affects food consumption among housewives living in Santa Maria / RS. The work focused on monitoring routine six housewives, belonging to the dominant classes, middle and popular, observing the consumption of food in supermarkets, their homes and daily practices of power. The methods applied for the research include ethnography, participant observation and in-depth interview. As a result, we realize that this is regional food consumption more directly in cultural references, choice of ingredients and rituals that effectively in the choice of brands.
\end{abstract}

Keywords: Food consumption. Regionalism. Gaúcho. anthropology of Consumption.

\section{Introdução}

No campo da comunicação, o trato do consumo é tradicionalmente relegado às pesquisas de comportamento e às medições de marketing, pelas quais se tenta desvelar os mecanismos de ação do consumidor em suas relações com produtos comunicacionais (campanhas, marcas, veículos etc.). Este texto parte de uma outra via, que entende o consumo como fato social complexo, cuja compreensão leva necessariamente à análise da cultura. Concordamos com Rocha (2006a), para quem os meios de comunicação têm o papel de, a partir da produção, oferecer um sistema classificatório que relaciona produtos/serviços às nossas experiências de vida, num processo contínuo de socialização para o consumo. A análise do consumo, assim, revela a expressão cultural de princípios, estilos de vida, valores e identidades.

No caso desta pesquisa, analisamos o consumo em relação aos valores regionais da cultura gaúcha. Como recorte, optamos por trabalhar o consumo de gênero alimentício, por entender que a alimentação (envolvendo seus rituais, símbolos e valores) é também uma forma de observar os traços culturais de um determinado grupo.

Partindo do princípio que a relação entre cultura e consumo implica a execução de uma análise qualitativa, consideramos um contexto cultural específico a ser observado. No caso deste trabalho, nos restringimos à cidade de Santa Maria - Rio Grande do Sul. É importante lembrar que este estado possui os traços culturais marcadamente tradicionais e regionalizados, cuja origem está historicamente ligada à ocupação de seu território e à fundação da sua economia (JACKS, 2003, p. 13).

Do ponto de vista mercadológico, marcas de diversos setores se apropriam desse simbolismo regional para valorizar-se e aproximar-se do seu público consumidor ao partilhar o "orgulho de ser gaúcho". O consumo, desse modo, relaciona-se diretamente com a cultura como uma via de mão dupla: tanto fortalece os valores e símbolos culturais locais como deles se apropria para se fortalecer.

Diante desse contexto, investigamos a interferência do regionalismo no comportamento de consumo das donas de casa, compradoras de produtos alimentícios. Para isso, foram acompanhadas seis donas de casa de Santa Maria (RS), sendo divididas equitativamente entre representantes da classe popular, classe média e classe dominante ${ }^{1}$.

\section{Antropologia do Consumo}

Esta pesquisa busca compreender como os aspectos culturais e simbólicos permeiam as relações entre pessoas e bens, pois tudo que consumimos está impregnado de valores e inserido em um sistema cultural comum a todos, mais especialmente artigos

\footnotetext{
O critério para esta divisão baseou-se na proposta de Quadros e Antunes (2001), que tem como referência para a classificação a profissão do chefe da família. Esta distinção considera, especialmente, a intenção de contemplar diferentes realidades socioeconômicas, uma vez que o consumo de alimentos pode ser regulado também conforme a disponibilidade financeira das famílias em questão.
} 
alimentícios, e suas articulações com aspectos regionais.

Tendo em vista a necessidade de observar os fatores culturais como influenciadores do consumo, recorre-se a Everardo Rocha (2005, p. 1), para quem o consumo é um "sistema cultural central na sociedade moderno-contemporânea". Em meio a este novo modelo de sociedade, moderno-capitalista, uma "nova configuração social trouxe a esfera cultural à tona" (SANTOS, 2011, p. 126), desta maneira os aspectos culturais são os influenciadores e modificadores desta sociedade, ligados ao consumo.

Os bens de consumo, dentro deste novo modelo de sociedade, não são um elemento funcional, mas algo carregado de signos que diferencia seus usuários. Assim, o consumo é tido como "um operador, gerenciando a distribuição de valores (sensualidade, poder, saber, bom gosto, cultura, sofisticação, beleza e outros tantos) que classificam e posicionam grupos e objetos no interior da ordem social" (ROCHA, 1995, p. 154).

É perceptível que o bem só possui sentindo dentro de um contexto, relacionado a outros objetos dentro de um sistema de significados, formando um "código que sujeita toda uma sociedade [...] A lógica do consumo ultrapassa os próprios objetos, construindo-se como uma prática idealista e não como uma prática material"' (SANTOS, 2011, p. 126).

Ao eleger ou excluir um bem de consumo o indivíduo está se expressando, revelando os seus valores, aderindo a algum grupo social. O reconhecimento, a partilha e a manutenção desses signos pelos grupos sociais revelam a circularidade da cultura e a sua existência como processo. Este processo não é apenas externado pelos indivíduos, mas sim existe por intermédio deles, perpassando-os, tornando-os sujeitos a partir desta relação.

Podemos dizer que as mudanças no processo cultural da vida em sociedade também cabem à reestruturação do valor do local, nacional e do global, que interferem no consumo dos indivíduos: as culturas regionais continuaram a existir apesar da globalização. O que se altera são as formas de perceber como "as identidades étnicas, regionais e nacionais, se reconstroem em processos de hibridização intercultural" (CANCLINI, 1995, p. 148).

Nesta pesquisa, tendo como base outros estudos a respeito do regionalismo, buscamos compreender como produtos reconhecidos como regionais podem ter a preferência ou não das consumidoras (donas de casa) em relação às marcas nacionais e multinacionais do gênero alimentício. Em meio a um gênero, como o de alimentos, em que uma forte tendência do mercado é massificar os produtos e as mais variadas opções de compra, pode-se inferir que os produtos regionais perdem o seu espaço mercadológico. Porém a bagagem simbólica e cultural que esses produtos trazem podem fazer com que eles se sobressaiam.

\section{Categorias para pensar o consumo alimentar}

Em relação ao consumo de alimentos, é importante observar que este não se restringe à satisfação de uma necessidade básica de sobrevivência. Nesta pesquisa, exploramos seus vínculos com o regionalismo. A alimentação deve ser entendida como um processo social complexo que envolve várias esferas da sociedade (ROMANELLI, 2006, p. 35), envolto por várias formas de saber. Esse conhecimento pode se dar a partir das origens, das tradições, do modo como é servido, preparado, dos comportamentos culturais, e estabelece relações compreendidas pela sociedade (LIMA FILHO; SPANHOL; OLIVEIRA, 2007).

Esta pesquisa se formula nas categorias de análise proposta por Canclini (1995), as quais servem como guia para compreender o quanto cultura e consumo estão atrelados: o consumo como modo integrativo, o consumo como ritual, o consumo como modo distintivo e comunicativo e o consumo midiático. Importa perceber que as categorias não são excludentes, mas, em muitos casos, complementares. Na perspectiva de Canclini (1995), o consumo, do ponto de vista integrativo, possibilita que o indivíduo se reconheça como pertencente a um determinado grupo.Aqui buscamos investigar essa categoria sob alguns aspectos: 1) como a influência do local (regional) afeta no sentimento de pertença ao grupo; 2) se a opção por produtos da culinária local representam para estas entrevistadas uma afirmação da sua regionalidade.

A segunda categoria aborda o consumo como ritual. Para Canclini (1995, p. 58), alguns estudos associam os ritos às celebrações, sendo esta 
uma forma que a sociedade busca para a sua organização racional. Podemos perceber que o alimento é um tipo de bem cultural e que as refeições têm o funcionamento semelhante ao de um ritual. Desse modo, a refeição é tida como um hábito, presente na rotina dos sujeitos de modo ritualizado, pois obedece a uma certa recorrência (horários, lugares e formas de se alimentar), tem uma função (socializar, demarcar atividades) e um significado (celebrações e valores locais).

A intenção é investigar de que modo a regionalidade (por meio dos signos materiais e simbólicos da alimentação) está inserida nos rituais alimentares no cotidiano das donas de casa entrevistadas. Também nos interessa perceber como as donas de casa veem as refeições em família, com os amigos e outros grupos, e se esses rituais são, para elas, uma forma de expressar a regionalidade.

Pensar o consumo alimentar como ato distintivo e comunicativo implica percebê-lo como um elemento que permite ao sujeito comunicar e marcar sua posição perante os demais na sociedade em que vive. O Estado do Rio Grande do Sul, na construção da sua identidade culinária, sofreu influências da imigração europeia, dos povos indígenas e dos negros. Esta miscigenação deu origem ao que hoje nomeamos como os pratos típicos do estado, reconhecidos em qualquer lugar como a identidade do povo gaúcho. Segundo Mintz (2001, p. 39), "comidas cotidianas, prosaicas, que tendemos a considerar comuns, escondem histórias sociais e econômicas complexas". Interessa-nos perceber, portanto, de que modo esses alimentos estão presentes e são interpretados como símbolo de distinção cultural para as mulheres entrevistadas.

A quarta e última categoria de análise diz respeito a quanto o mercado se apropria das questões culturais para se aproximar dos consumidores. Nesse sentido, existem vários estudos ${ }^{2}$ que investigam a apropriação regionalismo pelo mercado no caso específico do Rio Grande do Sul e que colocam a possibilidade de a publicidade sulista ter colaborado com este movimento de "afirmação da identidade regional" ao agregar os valores culturais e regionais a produtos para vendê-los (JACKS, 2003).
O mercado busca suprir necessidades e agregar novos valores e desejos ao consumidor. Nesse contexto, a comunicação tem uma participação importante como elemento informativo e influenciador do consumo. Com inúmeras marcas disponíveis, o consumidor tenta buscar aquelas que melhor o representem, que expressam a sua identidade. Em contrapartida, as marcas se apropriam desses valores (presentes na cultura) como forma de se aproximar mais do consumidor. Para este estudo importa perceber que o mercado faz uso dos bens culturais a fim de se aproximar, de criar identidade com público, como forma de trabalhar a aprovação da marca/empresa/produto.

Outro aspecto importante nesta análise do ponto de vista mercadológico e econômico é entender as percepções das donas de casa perante o consumo de produtos locais - abrangendo, para tanto, produtos que utilizam (ou não) na sua comunicação a estratégia da regionalidade, mas que são reconhecidos como locais.

\section{Aporte metodológico}

Para que se possa observar os hábitos alimentares, as preferências, as influências culturais, os modos de percepção sobre o regionalismo por parte das entrevistadas, éimprescindível que se possa acompanhá-las em seu cotidiano. Assim, o estudo de consumo privilegia "a captação das práticas/formas culturais em fonte primária, vale dizer, um conhecimento oriundo do trabalho de campo prolongado com nossos informantes/interlocutores que se baseia na relação pessoal entrepesquisadorepesquisado" (RONSINI,2011,p.3).

É importante caracterizar esta pesquisa como um estudo de caso, pois estamos tratando de um fenômeno, o consumo de alimentos, dentro de um contexto empírico particular (que envolve a rotina de seis donas de casa de classes sociais distintas - duas da classe dominante, duas da classe média e duas da classe popular-tidas como amostra qualitativa representantes deste universo).

Tendo em vista a necessidade de manter maior aproximação com as donas de casa, optamos pela

\footnotetext{
Ver Lisboa Filho e Silva (2011); Trindade (2010).
} 
etnografia, método a partir do qual procuramos compreender, por meio da imersão na "cultura do outro", os traços sociais, culturais, identitários para interpretar os significados. O percurso etnográfico iniciou-se a partir de visitas nas casas das famílias, para apresentar o trabalho a ser realizado e conhecer a rotina doméstica.

É importante mencionar também o papel da observação das residências. Foram observados o local onde fica a residência, o tipo da habitação, da decoração, que representam como é o estilo de vida e a identidade daquelas famílias. Como lugar privilegiado de observação do consumo alimentar no ambiente doméstico, foram observadas as despensas, para confirmar o quê, quanto e com que frequência se consome.

Outra etapa da pesquisa foi a observação participante das compras alimentícias no supermercado. Por fim, utilizamos a entrevista em profundidade com perguntas abertas a respeito do tema. Na pesquisa etnográfica, é realizada após a aproximação com o ambiente eoindivíduo observado. A seguir apresentamos a Tabela $1 \mathrm{com}$ a síntese dos perfis das mulheres pesquisadas:

Tabela 1 - Dados das entrevistas

\begin{tabular}{l|l|c|l}
\hline Nome & Classe & $\begin{array}{c}\text { Residentes } \\
\text { na casa }\end{array}$ & $\begin{array}{c}\text { Profissão } \\
\text { Chefe Família }\end{array}$ \\
\hline Ana & Dominante & 5 & Médico \\
Antonia & Dominante & 5 & Agropecuário \\
Bruna & Média & 2 & Engenheiro \\
Barbara & Média & 3 & Empresário \\
Cleusa & Popular & 4 & Auxiliar construção \\
Carmen & Popular & 4 & Aposentado \\
\hline
\end{tabular}

Fonte: Pesquisa de campo.

\section{Análise dos dados}

Os valores que remetem à identidade regional, como a virilidade, a rudeza, a belicosidade, a franqueza e o trabalho nas lidas campeiras (LISBOA FILHO, 2009, p. 71) reforçam a ideia do gaúcho como homem valente, desbravador, que comanda a família e o campo. Porém, esta pesquisa se propôs a analisar um grupo diferente dessa representação, as donas de casa de Santa Maria, para estudar como o regionalismo se faz presente no consumo de alimentos, o que pressupõe considerar na análise do regionalismo, o modo como as próprias entrevistadas se apropriam desta imagem.

A análise que segue pretende explicitar de que maneira o consumo e a cultura estão engajados nas práticas cotidianas das donas de casa. Os dados serão tensionados e explicitados conforme as categorias de análise apresentadas anteriormente.

\section{Consumo integrativo: o alimento e a cultura}

Corroborando com a primeira categoria de análise de Canclini (1995), o consumo como modo integrativo, percebe-se, durante o discurso das entrevistadas, que o consumo de alimentos, o momento das refeições, as práticas da alimentação constituem um modo de integração, não somente entre a família, mas também entre grupos e sociedade.

Para compreender os parâmetros pelos quais estas donas de casa constroem sua representação de regionalismo, procurou-se levantar suas percepções sobre o Estado do Rio Grande do Sul. De um modo geral, ficou evidente entre todas um sentimento de valorização do lugar em que nasceram e vivem.

A imagem que eu tenho é que nós aqui somos gratos a nossa miscigenação aqui do alemão, do italiano, eu acho que nós aqui somos um estado a parte com gente diferente, não querendo assim nos achar melhores, de jeito nenhum, mas que nós somos realmente diferentes do resto somos (Ana).

Bah é eu sou bem bairrista, vejo tudo que tem de bom aqui até pelas culturas diferentes que tem né, por tudo. Então a gente pega uma tradição boa, culinária de quantas tradições e cultura tudo. Eu não saio mais daqui (Bruna).

Tendo base em valores como coragem, garra, trabalho que norteiam a gauchidade (LISBOA FILHO, 2009) do povo local, percebe-se o orgulho da terra, uma exaltação quando se fala do Rio Grande do Sul no discurso das entrevistadas. O orgulho de ser gaúcho está explícito no hino rio-grandense, na literatura, na música, nas danças e no cotidiano de cada gaúcho. A mídia reconhece isso e faz uso dele em seus discursos.

É possível perceber nas entrevistadas o quanto os valores regionais da cultura se fazem 
presentes no modo como elas percebem a si próprias e ao lugar em que vivem. Quando indagadas a respeito do que elas identificam como sendo algo típico do gaúcho, o que seria um dos símbolos da cultura, o chimarrão, se faz um hábito comum. "O chimarrão. Todo o dia, três vezzes por dia, de manbã, de meio-dia e de noite" (Cleusa).

O chimarrão é um costume habitual para quem integra esta cultura. Esta "bebida com água quente e erva-mate" consumida em dias quentes e frios, em todos os lugares, compartilhada por todas as pessoas que estiverem se socializando no momento, é também um momento de afirmação da sua identidade e uma "forma de transmitir aos descendentes esta herança simbólica e cultural" (LIMA FILHO et al., 2011, p. 8).

Observando as práticas alimentares que, segundo as donas de casa, identificam alguém como pertencente à cultura sulista, outro símbolo que se fez presente nos relatos foi o consumo da carne, o churrasco. Para Calvete (2009, p. 13), "'a presença do churrasco na cultura regional, que sempre apareceu como uma forma de comemoração entre amigos e (ou) familiares em datas ou momentos especiais".

O consumo como modo integrativo apresenta o regionalismo como um fator que cria um vínculo entre as pessoas em sociedade. Nesta categoria, dois pontos foram problematizados: 1) para as entrevistadas, percebe-se que o fazer parte da cultura gaúcha é consumir os seus bens culturais como o churrasco e o chimarrão, valorizar a vida no campo, mesmo que não seja uma prática conhecida por todos; 2) quando as donas de casa se identificam por consumir as práticas típicas do gaúcho, carregam em sua fala um tom de orgulho, exprimindo o valor de seus hábitos como algo local e de caráter positivo.

\section{Consumo e os rituais alimentares}

O preparo do alimento, a escolha do cardápio, as preferências da família, o momento da refeição, a ida ao supermercado, as feiras e casa de carne são processos alimentares que representam rituais, porque compartilham de um bem comum, o alimento, que é um bem simbólico, atrelado a uma atividade que se constitui pela recorrência.

A valorização do alimento em torno das reuniões é bem explicitada pelas donas de casa. Os alimentos são um fator integrante que também engrandecem os momentos de comemoração. Oferecer, servir um prato, uma refeição é uma maneira de valorizar o momento em que as pessoas estão em relação, pois, pela óptica das donas de casa, as pessoas se reúnem em "volta da mesa". O alimento servido ou preparado é algo para honrar as refeições, é suporte para criação e manutenção de relações e não é destinado apenas a “alimentar" (ROMANELLI, 2006, p. 334).

Observando por essa perspectiva é que se percebe que existem alimentos que são considerados "nobres", que podem engrandecer uma refeição. Para as donas de casa desta amostra, o que pode valorizar o momento das refeições não está atrelado a produtos e marcas, mas sim a pratos preparados por elas mesmas, como a carne.

\section{Cada familia tem uma tradição ou o seu prato típico, que só faz quando tem festa ou sei lá, quando se reúnem, mas aqui pra nós mais é o churrasco né (Bruna). \\ Um bom prato bem feito. Ah tem vários, uma carne assada, uma carne de porco, uma farofa alouma coisa que acompanha, vários pratos (Carmen).}

Entre seus rituais alimentares cada uma tem suas particularidades e preferências; entretanto, um ponto se torna comum entre todas, que é o fazer. Quando se aborda a respeito de algo especial ou característico, cada mulher expressa as preferências das pessoas da família, mas o que mais as valorizam é o fato de elas fazerem aquele prato.

É importante realçar que o churrasco é um prato preparado para reuniões entre pessoas, família, amigos, colegas. Tendo em vista o caráter regional desta prática alimentar, é perceptível a interferência nas próprias moradias, pois em todas as casas há uma churrasqueira.

Durante a observação, uma das pesquisadoras teve a oportunidade de participar de um churrasco com uma entrevistada, que fez questão de apresentar todo o processo, o preparo da comida que acompanha, a área da churrasqueira, no momento da refeição, o modo como as pessoas se reúnem em volta da carne, a grande quantidade de comida. Este ritual indica como o churrasco gaúcho é diferente do preparado nos outros estados. O que é confirmado pela percepção das donas de casa sobre as características regionais da alimentação, que remete à diferença do churrasco gaúcho pela fartura. 
A ida ao supermercado também pode ser vista como um ritual que envolve o consumo. A escolha do local de compra, como os produtos são acomodados, a escolha dos produtos, como isso atrai o público, e as percepções da própria dona de casa a respeito do local estão todos incluídos nesse ambiente de ritualização. Durante a análise, uma das pesquisadoras teve a oportunidade de acompanhar esse ritual e observar a relação entre a estruturação do ponto de venda e as escolhas das donas de casa. Quanto às preferências ao local de compra, percebem-se nuances, mas na maioria a prioridade é por locais que sejam menores e com pouca fila, prevalecendo os mercados de bairro (de porte menor), com exceção da classe popular que opta por onde tenha mais opções como os hipermercados onde encontram a maior variedade e em quantidades maiores.

\section{Consumo alimentar como ato distintivo e comunicativo}

As percepções que temos de nós mesmos e como entendemos como as pessoas nos veem implicam o modo como nos comunicamos. O que elegemos como práticas alimentares comunicam o tipo de pessoa que queremos representar. Ter hábitos mais saudáveis, comer o que é de preferência, possuir uma alimentação simples, são características presentes no discurso das donas de casa quando se questiona o que é alimentação e como ela descreve a rotina alimentar.

As donas de casa compartilham a ideia de que alimentação é a entrada dos nutrientes para o corpo, é vital para a sobrevivência. Quando se observa a alimentação diária, o prato que representa esta ideia de nutrir o corpo, de dar sustância, é o arroz e o feijão, presente em todas as classes, e sendo endossado pela noção de um alimento saudável, nutritivo e substancial. Para as entrevistadas, as pessoas que moram no interior se alimentam melhor, pela possibilidade de realizar suas refeições em casa.

O tipo de alimentação que as mulheres preservam indica o modo como acreditam que são vistas quanto ao consumo de alimentos e as suas práticas alimentares. Quando indagadas sobre como os outros as percebem em relação à alimentação, é interessante notar que se constroem a autoimagem e a percepção de estilo de vida das entrevistadas.
Como uma neurótica, quando os filhos eram pequenos eu era conhecida como a mulher dos potes, porque tinha que ser tudo natural, feito na bora (Bruna). Eu acho que as pessoas só porque me olham e vêem que eu sou gorda, acham que eu cozinho bem (Cleusa).

Para percebê-las numa expectativa de projeção e observar a imagem pretendida que elas constroem, questionamos como gostariam que as pessoas as vissem. Curiosamente, a maioria delas deseja que seja de um jeito diferente, embora mantendo o seu estilo de vida. O que projetam se refere a uma satisfação pessoal, que seja reconhecida pelo que ela realiza.

Contudo, quando se aborda a distinção de papéis da dona de casa das outras pessoas da família, essas nuances não estão tão presentes nas suas falas. Mas, mediante a observação de pesquisadora no ambiente familiar, vê-se que existe uma diferença, inclusive no que diz respeito à classe social. Enquanto a dona de casa de classe dominante se afirma como simples, que realiza uma alimentação trivial, faz sugestões como o vinho à mesa. Do mesmo modo, ingredientes diferenciados no preparo de uma comida, além da presença de uma funcionária responsável pelo preparo da comida, marcam a diferença entre as casas. Já as donas de casa de classe popular vivem uma realidade diferente, pois, além de ter a prática de fazer todos os pratos, não têm o hábito de sair para realizar refeições. A alimentação popular consiste basicamente no que é preparado pela própria dona de casa, com as marcas que são de sua preferência.

O sentimento de ser vista de forma diferenciada pelas donas de casa se salienta mais quando ela serve um prato de doce, feito por ela mesma. A sobremesa, como elemento finalizador do ritual da alimentação, é tida como elemento especial, indica a intenção de agradar o outro e também comunica regionalidade: "Um bolo caseiro, uma sobremesa feita por mim, uma ambrosia, continua sendo algo típico gaúcho" (Antonia).

Percebe-se que, nesse contexto, os objetos de distinção se fazem mais presente em práticas de consumo do que propriamente em produtos. As diferenças entre classes se tornam mais claras por meio do que se possui como uma forma de comunicar o estilo de vida. Desse modo, os fatores regionais presentes nas outras categorias são novamente invocados no consumo distintivo e comunicativo, 
pois a imagem do gaúcho, e de tudo que ele representa, apresenta a cultura regional como distinta das demais, comunicando a forma como as pessoas se veem e os modos como expõem isso por meio do consumo alimentar.

\section{Apropriações do mercado no consumo alimentar}

A mídia se apropria de valores culturais regionais para se aproximar do público. Para Jacks (1998), a identidade regional é afirmada em produtos pela mídia. O produto que compreende o universo do cliente utilizará da melhor maneira as estratégias discursivas para atingir seus objetivos mercadológicos. "A figura do gaúcho reúne as características reconhecíveis por todos, provenientes de um passado de histórias de vitórias e conquistas, agora repassando ao produto em questão" (STEVENS, 2011, p. 146).

A respeito de consumo de alimentos, cada indivíduo tem suas preferências em razão de escolhas pessoais, porém é comum que todos tenham critérios de avaliação na hora do consumo de um produto. O fator qualidade é um pré-requisito imprescindível para as donas de casa. Como gostam de preparar a refeição da família, não elegem seus produtos sem ter conhecimento da qualidade que ele apresenta.

\section{A qualidade, algumas marcas que eu sei que é melhor eu nem olho para outra, tem que ser aquela. Se é produto fresco fruta, verdura, carne tem que ver as condições de como ta, e qualidade (Bruna). \\ Sim, coisa de segunda eu não gosto, tu vai comprar um arrozpequeninho, por um pouquinho menos, tu vai cozinhar ele empapa tudo. Tem que ser coisa boa, farinha se não é branca o pão fica preto, as coisas que é melhor. Senão, não presta (Carmen).}

No que diz respeito às percepções de consumo, a dona de casa de classe alta considera alguns critérios que são trabalhados pelo marketing, como a marca, a embalagem e as certificações de qualidade. Observando o valor de marca, muito almejado pelos profissionais do marketing, percebe-se que as marcas possuem importância para as entrevistadas, a ponto de dar respaldo no momento da escolha ou experimentação de um produto.
Quanto à importância, as opiniões são favoráveis à marca em todas as classes.

As marcas surtem mais efeitos com as classes média e popular, que não compram o produto caso não tenha a marca de sua preferência. Já as de classe dominante, caso o produto de sua marca habitual não esteja disponível, elas o substituem por outro facilmente.

Observamos que a influência da mídia no consumo alimentar é relativa, uma vez que as donas de casa afirmaram que já se sentiram atraídas por algum esforço da mídia, mas não sabem informar se esse comportamento se perpetua até hoje. As marcas regionais são produtos fabricados localmente, que movimentam a economia e, segundo alguns estudos, geram simpatia por ter o caráter local. No entanto, para as donas de casa há o comportamento de compra de produtos locais, mas que não são reconhecidos por elas como um movimento de valorização ou escolha consciente do regional. Inclusive, em alguns casos a dona de casa não percebe a diferença entre produtos locais e nacionais. Assim, quando se solicita que sejam nomeadas algumas marcas regionais, são poucas que conseguem identificá-las facilmente.

Ah eu costumo como a farinha Antoniazzi, massas Corrieri, a Cirilinha, que não tem mais que era um guaraná nosso muito gosto feito de um limão siciliano, que não tem mais, são coisas bem nossas (Ana). A Maria Inês é daqui? (Antonia)

Olha o que eu diria para você a salada hidropônica que é vendida pelo Peruzzo eu gosto muito, sabe como eu te disse dessas feiras, feira da solidariedade assim a gente compra muito produto bom né, como queijo, salame, coisa assim a gente compra (Barbara).

Sim tudoédaqui não éde fora, étudo local(Carmen).

Observando os produtos regionais do gênero alimentícios, nota-se que a comunicação do regional ("o ser gaúcho") é usada de maneira discreta como estratégia de identificação e aproximação com o público. Quando o conceito é usado, nem sempre o produto é reconhecido como regional pelas consumidoras entrevistadas.

Embora as donas de casa tenham expressado um forte apego à cultura local, a predileção pelas marcas já consumidas se mostra mais forte que o apelo regional. Desse modo, quando indagadas se 
substituiriam suas marcas tradicionais por marcas locais, a fidelidade pelas marcas habitual não possibilita esta mudança.

Vale ressaltar que esta análise se restringe à categoria alimentos, em que existem marcas nacionais (ou multinacionais) muito fortes e tradicionais, e isso colabora para a percepção de qualidade por parte das entrevistadas, o que é imprescindível para este setor em específico. Do mesmo modo, é preciso considerar que o ramo alimentício tem muitos produtos cuja semelhança (pelo caráter de pouco processo industrializado, como arroz, feijão, farinha) torna o trabalho de diferenciação das marcas mais desafiador.

\section{Considerações finais}

Quando aproximamos as noções de comunicação e consumo, estamos tratando de circulação e apropriação de signos que se constroem em relação, e que, portanto, são negociados, afirmados, modificados de modo concomitante a que são explicitados. Nesse contexto, quando falamos dos valores regionais no consumo alimentar, o exercício proposto por este artigo é parte da necessária tarefa de observar os códigos oriundos da cultura que constituem sentido na esfera de produção, para que se perceba o que viabiliza o consumo e suas práticas (ROCHA, 2006b, p. 85).

Pelo viés comunicacional, é possível afirmar que os códigos que sustentam o consumo de bens materiais e simbólicos se tornam públicos e visíveis pelos meios de comunicação. Estes veiculam significados que são apropriados e negociados pelos sujeitos de acordo com suas experiências singulares e coletivas.

Entendemos, assim, que os valores regionais circulantes na cultura são tensionados pelas donas de casa tanto pelo discurso presente nos meios quanto a partir de outras mediações relevantes (família, escola, classe). Os produtos alimentícios, foco desta pesquisa, estão imbuídos desses valores regionais e, a partir de uma associação coletiva e também subjetiva, transferem essa significação aos seus consumidores.

Neste estudo, portanto, partimos do princípio que os hábitos alimentares constituem a imagem da própria sociedade (BONIM; ROLIM apud GIMENES, 2010, p. 87). Assim, valores regionais ou da gauchidade se confirmam presentes nas práticas cotidianas das entrevistadas. Bens simbólicos como o chimarrão e o churrasco, que fazem parte da culinária gaúcha, são recorrentes em todos os discursos. Da mesma forma com que são práticas que fazem com que as donas de casa se identifiquem como sul-rio-grandenses.

Foi perceptível também que este apego aos valores regionais, o orgulho da terra, o cultivo às tradições, transmitidos para as novas gerações, são características fortes quando se fala sobre o consumo de alimentos. Ficou evidente a lacuna que existe quando falamos da valorização das consumidoras a respeito das marcas regionais. Primeiramente pela falta de reconhecimento das marcas em si, pois havia dificuldade em expressá-las de forma espontânea. Além disso, há o apego às marcas tradicionais, que não permitia a troca pelas marcas locais/regionais. É interessante considerar que as marcas locais de alimentos, pela observação que fizemos nos pontos de venda, dificilmente comunicam regionalidade. Hipoteticamente, seria interessante observar a relação das donas de casa com essas marcas, tendo em vista a valorização da regionalidade em outros segmentos. Esses fatos apresentados permitem concluir que cruzar campos de estudos para pesquisar o consumidor é uma forma válida de compreender a ligação entre cultura, comunicação e consumo, sendo este um sistema classificatório e distintivo (e, por isso, comunicativo). Percebe-se que regional está presente no consumo de alimentos de forma mais direta nas referências culturais, escolhas de ingredientes e rituais do que efetivamente na escolha das marcas. A observação dessas motivações, como possibilidade futura de investigação, poderia apontar exequibilidades de posicionamento para as empresas do ramo de marcas locais, indicando a pertinência ou não de conciliar a estratégia da comunicação regional com outras virtudes que se mostram importantes para o público.

\section{Referências}

CALVETE, R. A. O processo de escolha da carne para o churrasco sob a ótica do consumidor gaúcho. 2009. Monografia (Especialização) - Programa de PósGraduação de Administração, Universidades Federal do Rio Grande do Sul, Porto Alegre, RS, 2009. 
CANCLINI, N. G. Consumidores e cidadãos: conflitos multiculturais da globalização. Rio de Janeiro: UFRJ,1995.

GIMENES, M. H. S. G. Reflexões sobre o consumo alimentar sob o viés do consumo simbólico. In: CONGRESSO INTERNACIONAL DE GASTRONOMIA - MESA TENDÊNCIAS, 2010, São Paulo. Anais... São Paulo: Centro Universitário SENAC, out. 2010.

JACKS, N. Mídia Nativa - Indústria Cultural e Cultura Regional. $3^{a}$ edição. Porto Alegre, RS: UFRGS, 2003.

LIMA FILHO, D. O.; SPANHOL, C. P.; OLIVEIRA, F. D. Marketing e ciências sociais: um estudo sobre a influência da cultura na alimentação. Trabalho apresentado no Congresso Virtual Brasileiro de Administração - Convibra, 2007.

LISBOA FILHO, F. Mídia regional: a gauchidade e formato televisual no Galpão Crioulo. 2009. Tese (Doutorado em Comunicação) - Programa de Pós Graduação em Ciências da Comunicação da Universidade do Vale dos Sinos, São Leopoldo, RS, 2009.

LISBOA FILHO, F.; SILVA, C. P.A Telenovela Araguaia e a Representação da Cultura Gauchesca. XXXIV Congresso Brasileiro de Ciências da Comunicação. Recife, PE, Setembro de 2011.

MINTZ, S. W. Comida e antropologia: uma breve revisão. Revista Brasileira de Ciências Sociais, v. 15, n. 47, out. 2001.

QUADROS, W. J.; ANTUNES, D. J. N. Classes sociais e distribuição de renda no Brasil dos anos noventa. Cadernos do CESIT, n. 30, out. 2001.

ROCHA, E. P. G. A sociedade do sonho: comunicação, cultura e consumo. 4.ed. Rio de Janeiro, RJ: Mauad, 1995.

ROCHA, E. P. G. Culpa e prazer: imagens do consumo na cultura de massa. Revista Comunicação, Mídia e Consumo, São Paulo, v. 2, n. 3, mar. 2005.

ROCHA, E. P. G. Coisas estranhas, coisas banais: notas para uma reflexão sobre o consumo. In: ROCHA, E.; ALMEIDA, M. I. M.; EUGENIO, F. (Orgs.). Comunicação, consumo e espaço urbano: novas sensibilidades nas culturas jovens. Rio de Janeiro: Mauad, 2006a. p. 15-34.

ROCHA, E. P. G. Representações do consumo: estudos sobre a narrativa publicitária. Rio de Janeiro: Ed. PUC; Rio de Janeiro: Mauad, 2006b.

ROMANELLI, G. O significado da alimentação na família: uma visão antropológica. Trabalho apresentado no Simpósio: Transtornos Alimentares: Anorexia e Bulimia Nervosas. Ribeirão Preto, MS, 2006.

RONSINI, V. V.A perspectiva das mediações de Jesús Martín-Barbero (ou como sujar as mãos na cozinha da pesquisa empírica de recepção. Associação Nacional dos Programas de Pós-Graduação em Comunicação Compós. Santa Maria, RS, 2011.

SANTOS, T. C. A sociedade de consumo, os media e a comunicação nas obras iniciais de Jean Baudrillard. Revista Galáxia, n. 21, jun. 2011.

STEVENS, L. Mídia, identidade e representação: uma análise da publicidade televisa da cerveja polar export. 2011. Dissertação (Mestrado em Comunicação Midiática) Programa de Pós-Graduação em Comunicação Midiática, Universidade Federal de Santa Maria, Santa Maria, RS, 2011.

TRINDADE, E. Vínculos de sentidos entre publicidade e marcas no consumo alimentar doméstico de famílias paulistanas: um estudo exploratório. Trabalho apresentado no XXXIII Congresso Brasileiro de Ciências da Comunicação. Caxias do Sul, RS, set. 2010.

Recebido: $18 / 08 / 2012$

Received: 08/18/2012

Aprobado: 05/09/2012

Approved: 09/05/2012 